\title{
Apolipoprotein E genotyping method by Real Time PCR, a fast and cost-effective
} alternative to the TaqMan and FRET $^{\circledR}$ assays

\section{Fast, cost-effective alternative for Apolipoprotein E genotyping}

\author{
Olga Calero ${ }^{1}$, Rafael Hortigüela ${ }^{2}$, María J. Bullido ${ }^{1,3}$ \& Miguel Calero ${ }^{1,2}$
}

${ }^{1}$ Consortium for Biomedical Research in Neurodegenerative Diseases (CIBERNED)

${ }^{2}$ Spongiform Encephalopathies Unit, National Centre of Microbiology, Institute of Health Carlos III (CNM-ISCIII), Madrid, Spain.

${ }^{3}$ Centre National of Molecular Biology Severo Ochoa (CSIC-UAM), Madrid, Spain.

*Address correspondence to Miguel Calero, Ph. D., Spongiform Encephatopathies Unit, National Centre of Microbiology, Institute of Health Carlos III (CNM-ISCIII), Ctra. Pozuelo Km2, Majadahonda 28220, Madrid, Spain. Tlf: +34 918223709. Fax: +34 915097919, e-mail: mcalero@,isciii.es

Type of Article: Short Communication

Key words: $A P O E$, genotyping, Alzheimer, Real Time PCR, SYBR Green

Abbreviations: ApoE (apolipoprotein E), PCR-RFLP (PCR-Restriction Fragment Length Polymorphism), ARMS-PCR (Amplification Refractory Mutation SystemPCR), SSP-PCR (Simple Sequence Specific Primer-PCR), FRET (Fluorescent Resonance Energy Transfer), NINCDS-ADRDA (National Institute of Neurological and Communicative Disorders and the Alzheimer's Disease and Related Disorders Association), Ct (Cycle Threshold), DMSO (Dimethyl sulfoxide).

Human Genes: $A P O E$ 


\section{Apolipoprotein E genotyping method by Real Time PCR, a fast and cost-effective}

\section{alternative to the TaqMan ${ }^{\circledR}$ and FRET assays}

Olga Calero ${ }^{1}$, Rafael Hortigüela ${ }^{2}$, María J. Bullido ${ }^{1,3}$ \& Miguel Calero ${ }^{1,2}$

${ }^{1}$ Centro de Investigación Biomédica en Red sobre Enfermedades Neurodegenerativas -

\section{CIBERNED}

${ }^{2}$ Unidad de Encefalopatías Espongiformes, Centro Nacional de Microbiología, Instituto de Salud Carlos III (CNM-ISCIII), Madrid, Spain.

${ }^{3}$ Centro Nacional de Biología Molecular Severo Ochoa (CSIC-UAM), Madrid, Spain.

* Address correspondence to Miguel Calero, Unidad de Encefalopatías Espongiformes, Centro Nacional de Microbiología, Instituto de Salud Carlos III (CNM-ISCIII), Ctra. Pozuelo Km2, Majadahonda 28220, Madrid, Spain. Tlf: +34 918223709. Fax: +34 915097919, e-mail: mcalero@,isciii.es

Number of text pages: 12

Number of figures: 1

Number of tables: 1

Number of supplementary figures: 1 


\begin{abstract}
The apolipoprotein E gene $(A P O E)$ polymorphism genotyping has an allegedly important predictive value for coronary heart disorders and Alzheimer disease. We developed a simple, fast, cost-effective and suited for high-throughput protocol for determining $A P O E$ genotypes by Real Time PCR monitored by $\mathrm{SYBR}^{\circledR}$ Green. The method is based on differential amplification by allele-specific primers. These primers have variations in their $3^{\prime}$-end nucleotides such that are specific for one of the two variants in each polymorphic position. By this protocol, we obtained a $100 \%$ concordance with the $A P O E$ genotypes determined by sequencing analysis. The main advantages of this method are its relative simplicity and the reduced cost compared to other methodologies, such as the TaqMan ${ }^{\circledR}$ and FRET assays.
\end{abstract}

Keywords: $A P O E$, genotyping, Alzheimer, Real Time PCR, SYBR ${ }^{\circledR}$ Green. 


\section{Introduction}

Apolipoprotein E (ApoE) is a $34 \mathrm{kDa}$ glycoprotein involved in lipid metabolism (Mahley, 1988). The human $A P O E$ gene coding for this protein is polymorphic and is located on chromosome 19 (Das et al., 1985). There are three common codominant alleles $-\varepsilon 2, \varepsilon 3$ and $\varepsilon 4-$ that encode three ApoE protein isoforms: $\mathrm{E}_{2}, \mathrm{E}_{3}$ and $\mathrm{E}_{4}$. These isoforms differ at the amino acid residues 112 and 158. Isoform $\mathrm{E}_{2}$ has cysteine residues at both sites, $\mathrm{E}_{4}$ has arginine residues at both sites, while $\mathrm{E}_{3}$, the most common form, has a cysteine at position 112 and an arginine at position 158 (Emi et al., 1988). These differences have profound effects on the biological functions of ApoE. The lipidbinding activities of these isoforms are different: $E_{2}$ and $E_{3}$ bind preferentially to HDL, whereas $\mathrm{E}_{4}$ prefers VLDL (Saito et al., 2003). These biochemical differences may be responsible for the association of the isoforms with different pathological processes. The isoform $\mathrm{E}_{4}$ is associated with a higher risk for coronary heart and Alzheimer's diseases. In contrast, isoform $\mathrm{E}_{2}$ shows a protective effect against Alzheimer's disease, but it is associated with familial type III hyperlipoproteinemia (Roses et al., 1994).

Thus, interest in $A P O E$ genotyping is high for epidemiological research and it is already recognized as valuable information that may help to identify individuals at increased risk for cardiovascular disorders, and it may as well be part of future diagnostic or predictive algorithms for individuals at risk of developing Alzheimer's disease.

Several methods are commonly used for genotyping the three major APOE haplotypes. The more frequent method has been traditionally PCR-RFLP (PCR-Restriction Fragment Length Polymorphism) analysis (Zivelin et al., 1997). However, it is a timeconsuming and error-prone method, due to possible incomplete restriction enzyme 
digestion. Capillary electrophoresis (Somsen et al., 2002), PCR plus sequencing or mass spectrometry (Srinivasan et al., 1998) are effective methods, but require expensive dedicated instrumentation. The ARMS-PCR (Amplification Refractory Mutation System-PCR) (Donohoe et al, 1999) and SSP-PCR (Simple Sequence Specific PrimerPCR) (Pantelidis et al., 2003) methodologies require analysis by agarose gels, thus limiting the number of samples that can be examined at a time. The Real Time PCR detection by fluorescence melting curves (Papp et al., 2003) is a simple and rapid method, but the formation of primer-dimers may complicate the melting curves interpretation. The use of FRET (Fluorescent Resonance Energy Transfer) (Rihn et al., 2009) and TaqMan ${ }^{\circledR}$ (Koch et al., 2002) probes in Real Time PCR are very effective, although costly methods.

We describe here an $A P O E$ genotyping protocol based in the SSP-PCR methodology adapted to Real Time PCR monitored by SYBR ${ }^{\circledR}$ Green. This genotyping method is based on differential amplification by allele-specific primers.

\section{Materials and Methods}

\section{Subjects}

The study was approved by Alzheimer's Disease Research Unit. CIEN FoundationReina Sofia Foundation, Institute of Health Carlos III Ethics Committee with the adequate understanding and written consent of subjects, family members or legal guardians, as appropriate. A total of 280 subjects diagnosed of probable Alzheimer according to NINCDS-ADRDA (McKhann et al., 1984) were analyzed. 


\section{Human genomic DNA isolation}

Genomic DNA was extracted from $2 \mathrm{ml}$ of human whole blood by NucleoSpin ${ }^{\circledR}$ Blood L kit (Macherey-Nagel) according to the manufacturer's instructions.

\section{Oligonucleotide primers design}

The primers have been designed from human APOE sequence (NG_007084.2, NCBI reference assembly sequence). The forward primers comprise from positions 2886 to 2903, whereas the reverse primers include from positions 3041 to 3058 . Their 3 '-end nucleotides are located on the polymorphic site, and the specific primers were designed to match one of the two variants at the 2903 and 3041 APOE positions (Table 1).

\section{DNA amplification by Real Time PCR}

The primers were combined in three reaction mixtures to yield a predicted amplification product of 173 bp: "Reaction ApoE2" (primers ApoE_112C and ApoE_158C), "Reaction ApoE3" (primers ApoE_112C and ApoE_158R) and "Reaction ApoE4" (primers ApoE_112R and ApoE_158R). Each PCR reaction mixture contained the following: 1x Power SYBR ${ }^{\circledR}$ Green PCR Master Mix (Applied Biosystems), $0.3 \mu \mathrm{M}$ of each primer and $50 \mathrm{ng}$ of genomic DNA. Negative controls were performed by using the same reaction mixtures without DNA. All the reactions were run in duplicate. The PCR amplification protocol was as follows: initial AmpliTaq Gold DNA Polymerase activation at $95{ }^{\circ} \mathrm{C}$ for $10 \mathrm{~min}$, followed by 40 cycles with denaturation at $95{ }^{\circ} \mathrm{C}$ for 15 $\mathrm{s}$, and annealing+extension at $62{ }^{\circ} \mathrm{C}$ for $1 \mathrm{~min}$. Amplification was performed either on a StepOne Real Time PCR System (48-well format) (Applied Biosystems), on a 7500 Real Time PCR System (96-well format) (Applied Biosystems), or on a 7900HT Real- 
Time PCR System (384-well format) (Applied Biosystems) by using the comparative $\mathrm{C}_{\mathrm{T}}\left(\Delta \mathrm{C}_{\mathrm{T}}\right)$ method (quantitation experiment setup).

\section{Standard APOE end-point PCR amplification and sequencing}

For validation purposes, all samples genotyped by the above-described Real Time PCR protocol were contrasted by standard end-point PCR amplification and DNA sequencing. In brief, all reactions were carried out with $100 \mathrm{ng}$ of genomic DNA and 1 unit of Taq DNA Polymerase (Applied Biosystems) in a volume of $25 \mu$ l. The final concentrations of other reactants were: $1 \mathrm{x}$ Taq DNA Polymerase Buffer, $0.1 \mathrm{mM}$ dNTPs, $0.5 \mathrm{mM} \mathrm{MgCl} 2,10 \%$ DMSO and $0.1 \mathrm{mM}$ of each primer (forward primer $5^{\prime}$ TGCCCGGCCTCCTAGCTCCTTC-3' and reverse primer 5'GAGGTGAAGGAGCAGGTGGCGGAG-3'). The PCR cycling conditions were as follows: initial denaturation at $94{ }^{\circ} \mathrm{C}$ for 3 min followed by 40 cycles of $94{ }^{\circ} \mathrm{C}$ for $30 \mathrm{~s}$, $72{ }^{\circ} \mathrm{C}$ for $30 \mathrm{~s}$ (decreased $0.4{ }^{\circ} \mathrm{C}$ in each cycle) and $72{ }^{\circ} \mathrm{C}$ for $90 \mathrm{~s}$ and a final extension at $72{ }^{\circ} \mathrm{C}$ for $7 \mathrm{~min}$. Amplification was performed on a Mastercycler epGradient $\mathrm{S}$ thermal cycler (Eppendorf).

An aliquot of $2 \mu 1$ of the amplicon product from above reaction (687 bp) was used for sequencing reactions $\left(\right.$ BigDye $^{\circledR}$ Terminator v1.1 Cycle Sequencing Kit, Applied Biosystems), using the above primers at the same final concentration. The amplified fragments were analyzed using an ABI PRISM ${ }^{\circledR} 377$ Analyzer (Applied Biosystems) and Chromas v 2.33 software.

\section{Results and Discussion}


In order to monitor in real time DNA amplification, the double-stranded DNAfluorescent dye $\mathrm{SYBR}^{\circledR}$ Green was included in all reactions for $A P O E$ genotyping. The "cycle threshold", or Ct value (fixed in the exponential phase of the amplification plot as the number of PCR cycles necessary to achieve a given level of fluorescence) was chosen as the informative Real Time PCR read-out for genotyping results analysis.

By this method and using the experimental conditions described above in a StepOne (48-well format), a 7500 (96-well format), or a 7900HT (384-well format) Real Time PCR Systems, we were capable of unequivocally discriminating the different $A P O E$ haplotypes on the basis of their $\mathrm{Ct}$ values (Figure 1). The presence/absence of haplotypes was determined by differential amplification with the three specific amplification setups for $\varepsilon 2, \varepsilon 3$ or $\varepsilon 4$ alleles. For example, an $A P O E \varepsilon 3 / \varepsilon 4$ heterozygous yielded Ct values for "Reaction ApoE3" and "Reaction ApoE4" significantly lower ( $\triangle \mathrm{Ct} \geq 5$ cycles) compared to "Reaction ApoE2". Whereas, an $A P O E \varepsilon 3 / \varepsilon 3$ homozygous showed a Ct value for "Reaction ApoE3" significantly lower than the Ct obtained for the other two reactions. If the lower $\mathrm{Ct}$ values were not in the expected range $(15 \leq \Delta \mathrm{Ct} \leq 25$ cycles), the assay was considered failed. In the experimental conditions here indicated for genotyping purposes, for the StepOne (48-well format) and the 7500 (96-well format) Real Time PCR Systems, Ct values lower than 25 indicated a positive amplification reaction, whereas $\mathrm{Ct}$ values higher than 25 was considered as a negative amplification (Figure 1). For the 7900HT Real-Time PCR System the reference Ct value was smaller, around 23 (data not shown). These differences appear to be related to the sensitivity and the threshold set-up defined for each system. Negative controls did not show amplification before cycle 35 in any of the systems. Amplification plots in a StepOne Real Time PCR System of the six different $A P O E$ haplotypes in the human population and negative controls are showed as Supplementary Figure. 
The difference in the $\mathrm{Ct}$ values between positive and negative reactions was in all cases and systems of at least 5 cycles, which indicates that the specific amplifications are more than 32-fold more efficient compared to the non-specific ones. All the samples genotyped by this method showed amplification patterns in perfect concordance with the $A P O E$ genotypes determined by sequencing analysis.

In order to explore the versatility and robustness of this genotyping protocol, we studied its applicability to lower amounts of DNA material and smaller reaction volumes. Total final volumes of the PCR reactions from 10 to $1 \mu$ were tested. In our hand, volumes down to $2 \mu \mathrm{l}$ were sufficient to distinguish between positive and negative reactions, whereas smaller volumes yielded erratic results, likely due to pipetting errors associated to our automatic volume dispenser system (data not shown). Different initial DNA amounts were tested (from $1 \mathrm{ng}$ up to $50 \mathrm{ng}$ ). With decreasing amounts of DNA, we observed that the $\Delta \mathrm{Ct}$ between positive and negative reactions were similar or smaller, but always sufficient to differentiate them (data not shown).

A number of methods have been developed for $A P O E$ genotyping. Traditionally, three methods have been commonly used, namely PCR followed by DNA sequence analysis, PCR followed by RFLP analysis, and PCR followed by Reverse Hybridization. Sequence analysis is very reliable, but time consuming and expensive method. PCRRFLP analysis (Zivelin et al., 1997) by mean of digestion of the fragment of the coding region of $A P O E$ with $H h a \mathrm{I}$ is an inexpensive, but error-prone method, due to possible incomplete restriction enzyme digestion or star activity that difficult the interpretation of results. Reverse Hybridization, as well as other methods recently developed, 
including capillary electrophoresis (Somsen et al., 2002), PCR plus sequencing or mass spectrometry (Srinivasan et al., 1998), and ARMS-PCR (Donohoe et al, 1999), are valuable and convenient techniques for small-scale investigators, but difficult to scaleup for large number of samples.

Ponchel et al. (2003) proposed the use of SYBR Green ${ }^{\circledR}$ to perform relative quantification of gene rearrangements, gene amplifications and micro gene deletions analysis as alternative to the $\operatorname{TaqMan}^{\circledR}$ methodology (Koch et al., 2002). The advantages were the relative simplicity and the reduced cost of SYBR Green ${ }^{\circledR}$ compared to TaqMan ${ }^{\circledR}$ probes. In here, we describe an extension of the use of SYBR Green ${ }^{\circledR}$ for $A P O E$ genotyping as a fast (approximately $2 \mathrm{~h}$ ), simple, sensitive, cost-effective and reproducible method alternative to the use of TaqMan ${ }^{\circledR}$ or FRET probes (Koch et al., 2002, Rihn et al., 2009). The reduced cost of our protocol is mainly related to the use of non-labelled primers instead of expensive labelled probes. Furthermore, because this method does not require post-PCR processing or other treatment steps, it represents an advantageous option to other SSP-PCR methods (Pantelidis et al., 2003). Thus, our method can readily be applied to high-throughput $A P O E$ genotyping programs.

\section{Acknowledgements}

Funding was provided by grants FIS 05/0912 from the Ministerio de Sanidad, CIEN Foundation and the Spanish CIBERNED network. We thank Ana Martínez García for her excellent technical assistance. 


\section{References}

Das HK, McPherson J, Bruns GA, Karathanasis SK, Breslow JL. Isolation, characterization, and mapping to chromosome 19 of the human apolipoprotein E gene. J Biol. Chem., 1985;260:6240-7.

Donohoe GG, Salomäki A, Lehtimäki T, Pulkki K, Kairisto V. Rapid identification of apolipoprotein E genotypes by multiplex amplification refractory mutation system PCR and capillary gel electrophoresis. Clin. Chem., 1999;45:143-6.

Emi M, Wu LL, Robertson MA, Myers RL, Hegele RA, Williams RR, White R et al. Genotyping and sequence analysis of apolipoprotein E isoforms. Genomics, 1988;3: $373-9$.

Koch W, Ehrenhaft A, Griesser K, Pfeufer A, Müller J, Schömig A, Kastrati A. TaqMan systems for genotyping of disease-related polymorphisms present in the gene encoding apolipoprotein E. Clin. Chem. Lab. Med., 2002;40:1123-31.

Mahley RW. Apolipoprotein E: cholesterol transport protein with expanding role in cell biology. Science, 1988;240:622-30.

McKhann G, Drachman D, Folstein M, Katzman R, Price D, Stadlan EM. Clinical diagnosis of Alzheimer's disease: report of the NINCDS-ADRDA Work Group under the auspices of Department of Health and Human Services Task Force on Alzheimer's Disease. Neurology, 1984;34:939-44.

Pantelidis P, Lambert-Hammill M, Wierzbicki AS. Simple sequence-specific-primerPCR method to identify the three main apolipoprotein E haplotypes. Clin. Chem., $2003 ; 49: 1945-8$.

Papp AC, Pinsonneault JK, Cooke G, Sadée W. Single nucleotide polymorphism genotyping using allele-specific PCR and fluorescence melting curves. Biotechniques, 2003;34:1068-72. 
Ponchel F, Toomes C, Bransfield K, Leong FT, Douglas SH, Field SL, Bell SM, et al. Real-time PCR based on SYBR-Green I fluorescence: an alternative to the TaqMan assay for a relative quantification of gene rearrangements, gene amplifications and micro gene deletions. BMC Biotechnol., 2003;3:18.

Rihn BH, Berahmoune S, Jouma M, Chamaa S, Marcocci L, Le Faou A. APOE genotyping: comparison of three methods. Clin. Exp. Med., 2009; 9(1):61-5.

Roses AD, Strittmatter WJ, Pericak-Vance MA, Corder EH, Saunders AM, Schmechel DE. Clinical application of apolipoprotein E genotyping to Alzheimer's disease. Lancet, $1994 ; 343: 1564-$

Saito H, Dhanasekaran P, Baldwin F, Weisgraber KH, Phillips MC, Lund-Katz S. Effects of polymorphism on the lipid interaction of human apolipoprotein E. J. Biol. Chem., 2003;278:40723-9.

Somsen GW, Welten HT, Mulder FP, Swart CW, Kema IP, de Jong GJ. Capillary electrophoresis with laser-induced fluorescence detection for fast and reliable apolipoprotein E genotyping. J. Chromatogr. B Anal. Technol. Biomed. Life Sci., 2002;775:17-26.

Srinivasan JR, Kachman MT, Killeen AA, Akel N, Siemieniak D, Lubman DM. Genotyping of apolipoprotein E by matrix-assisted laser desorption/ionization time-offlight mass spectrometry. Rapid Commun. Mass Spectrom., 1998;12:1045-50.

Zivelin A, Rosenberg N, Peretz H, Amit Y, Kornbrot N, Seligsohn U. Improved method for genotyping apolipoprotein E polymorphisms by a PCR-based assay simultaneously utilizing two distinct restriction enzymes. Clin. Chem., 1997;43:1657-9. 


\section{Legend to Figure 1}

Figure 1. Amplification plots (haplotypes vs. Ct) in a StepOne Real Time PCR System of the six different $A P O E$ haplotypes in the human population and negative controls (NC) ( $\varepsilon 2$ : circles, $\varepsilon 3$ : triangles and $\varepsilon 4$ : squares).

\section{Legend to Supplementary Figure}

Supplementary Figure. Amplification plots (cycle vs. $\Delta \mathrm{Rn}$ ) in a StepOne Real Time PCR System of the six different $A P O E$ haplotypes in the human population and negative controls ( $\varepsilon 2$ in red, $\varepsilon 3$ in green and $\varepsilon 4$ in blue). $\Delta \mathrm{Rn}$ is an indicator of the magnitude of the signal generated by the PCR reaction. 


\section{Table 1}

Table 1. Nucleotide sequence and characteristics of the primers used for $A P O E$ genotyping.

\begin{tabular}{|l|c|c|c|c|c|}
\hline & Orientation & Nucleotide Sequence 5'-3' & Tm $\left({ }^{\circ} \mathrm{C}\right)$ & $\% \mathrm{G}+\mathrm{C}$ & Length (bp) \\
\hline ApoE_112C & Forward & CGGACATGGAGGACGTGT & 56.3 & 61 & 18 \\
\hline ApoE_112R & Forward & CGGACATGGAGGACGTGC & 59.6 & 67 & 18 \\
\hline ApoE_158C & Reverse & CTGGTACACTGCCAGGCA & 55.1 & 61 & 18 \\
\hline ApoE_158R & Reverse & CTGGTACACTGCCAGGCG & 57.4 & 67 & 18 \\
\hline
\end{tabular}

Polymorphic bases are shown in bold. 


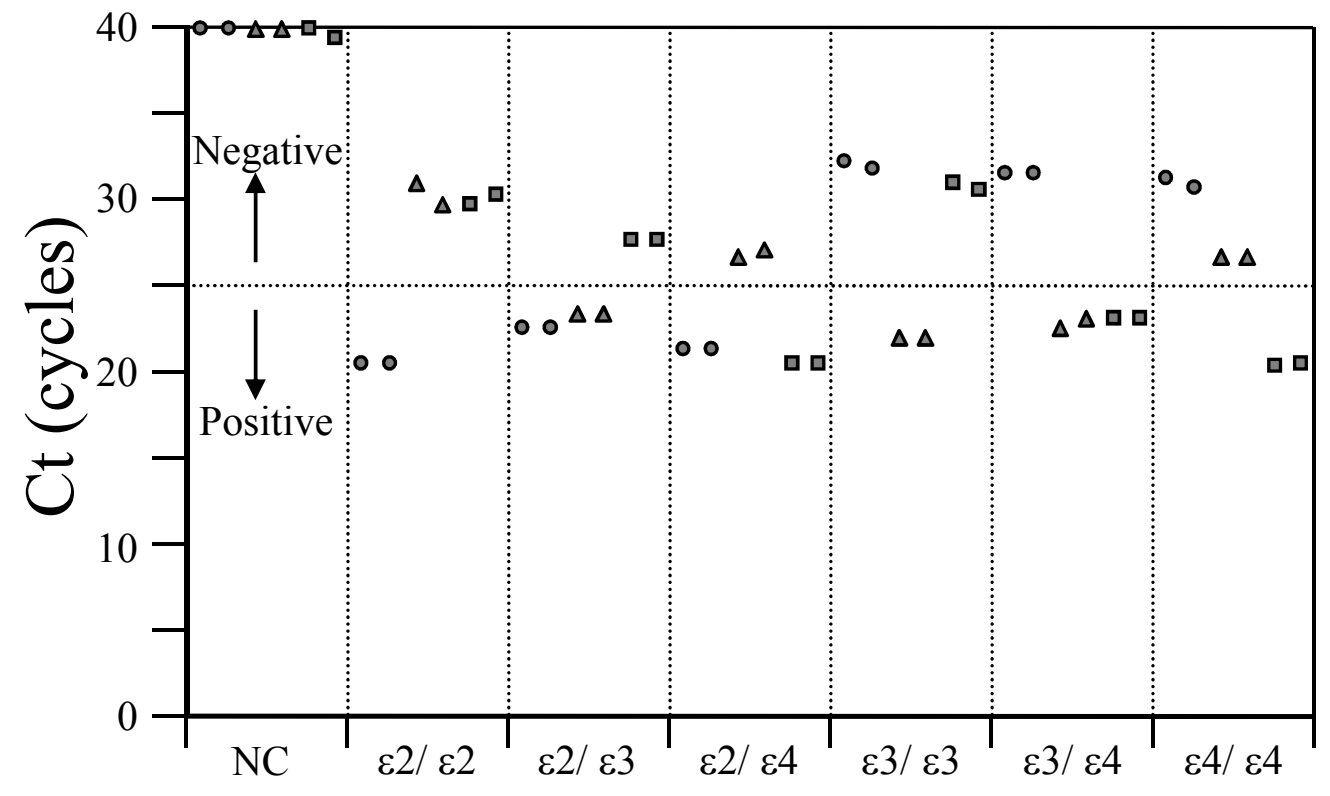

Haplotypes 

Supplementary file for online publication only
Click here to download Supplementary file for

Click here to download Supplementary file for online publication only: Calero et al_J Neurosci Methods_Supp_Figure_Apolipop ( (1) op 西 西 .

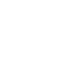

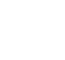

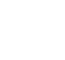

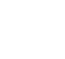

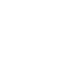
. . . . . . . . .

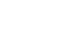

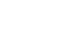
. . . . . . . . 